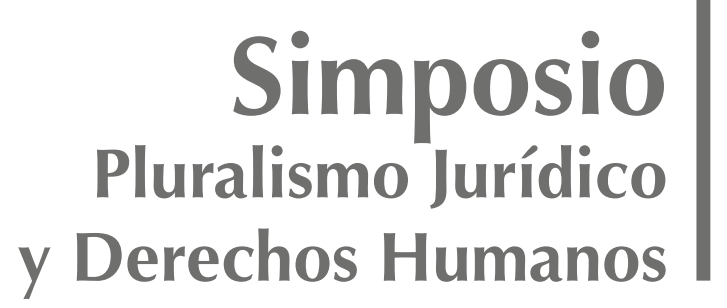


Alexei Julio-Estrada. Abogado, Doctor en Derecho de la Universidad Complutense de Madrid, docente de la Universidad Externado de Colombia. Actualmente Magistrado encargado de la Corte Constitucional de Colombia. alexeij@corteconstitucional.gov.co.

José Antonio Rivera Santivañez. Abogado de la Universidad Mayor de San Simón, Cochabamba, Bolivia. Magíster en Derecho Constitucional de la Universidad Andina Simón Bolívar, sede Sucre, Bolivia. Ex Magistrado del Tribunal Constitucional de Bolivia 1998-2006. Catedrático de Derecho Constitucional en la Universidad Mayor de San Simón, de la ciudad de Cochabamba, Bolivia, y docente de postgrado en universidades públicas y privadas del Estado Boliviano. Académico de número de la Academia Nacional de Ciencias Jurídicas de Bolivia, miembro del Instituto Iberoamericano de Derecho Constitucional, de la Academia Boliviana de Estudios Constitucionales y del Instituto Iberoamericano de Derecho Procesal Constitucional. Entre sus últimas publicaciones destacan El Proceso Constituyente en Bolivia. Reflexiones sobre la Reforma de la Constitución, Ed. Kipus, Cochabamba, 2005; El Tribunal Constitucional y protección de los Derechos Humanos, Ed. Tribunal Constitucional de Bolivia, Sucre, 2003; Hacia una nueva Constitución. Luces y Sombras del Proyecto modificado por el Parlamento, Ed. FUNDAPAC, La Paz, 2008; Temas de Derecho Constitucional, Ed. Olimpus, Cochabamba, 2012.

riverasa@gmail.com

Neus Torbisco. Doctora en Derecho Público por la Universidad Pompeu Fabra y actualmente profesora agregada al departamento de Derecho de esta misma universidad, donde imparte cursos relacionados con los derechos humanos, la teoría del derecho y la filosofía moral y política. A lo largo de su formación realizó estancias de investigación en las Universidades de Ottawa y Queen's (Canadá), en la Universidad de Bristol (Reino Unido) y en la Universidad de Siena (Italia). También realizó un internship en el Tribunal Europeo de Derechos Humanos. Tras finalizar su doctorado, la Global Law School de la Universidad de Nueva York le otorgó la prestigiosa Hauser Research Scholarship para realizar una investigación sobre diversidad cultural y modelos de integración política en democracias supranacionales. Posteriormente, desde 2007 a 2009 fue visiting academic en la London School of Economics (Reino Unido). También ha impartido cursos en las Universidades de Puerto Rico y Miami. Más recientemente, en el curso 2012-2013 ha sido invitada como profesora visitante en la escuela de Derecho de la Universidad de Harvard. La profesora Torbisco ha publicado artículos en diversas revistas nacionales y extranjeras y es autora del libro Group Rights as Human Rights, Springer, 2006.

neus.torbisco@upf.edu

Aresio Valiente López. Miembro del pueblo Guna, Comarca Guna Yala, Panamá. Se graduó de abogado en la Facultad de Derecho y Ciencias Políticas de la Universidad de Panamá. Cuenta con estudios superiores en propiedad intelectual, métodos alternos de resolución de conflictos, derechos humanos y docencia superior. Ha sido consultor de la OMPI, OIT, IIDH, entre otros. Cuenta con publicaciones en materia indígena. Es Director Ejecutivo del Centro de Asistencia Legal Popular, Presidente de la Unión Nacional de Abogadas y Abogados Indígenas de Panamá, Vicepresidente del Instituto de Derecho Agrario, Ambiental e Indígena y miembro del equipo legal del Congreso General Guna, gobierno autónomo del pueblo Guna.

diwigdi@hotmail.com

Raquel Z. Yrigoyen Fajardo. Abogada, Pontificia Universidad Católica del Perú (PUCP). Doctora en Derecho, Universidad de Barcelona (UB), con Maestría en Sistema Penal y Problemas Sociales (UB), con especialización en derecho consuetudinario indígena (Universidad Autónoma de México y Universidad San Carlos de Guatemala). Asimismo, ha realizado los siguientes diplomados: Diploma en Estudios Antropológicos (DEA-PUCP), Diploma en Criminal Justice and Critical Criminology (European Common Study Programme) y Comparative Federal Indian Law (University of Oklahoma). Fundadora y Vicepresidenta del Instituto Internacional de Derecho y Sociedad-IIDS / International Institute on Law and Society-IILS (www.derechoysociedad.org) ubicado en Lima, Perú. Consultora de la ONU y docente universitaria, siendo coordinadora de las Diplomaturas de Estudio Internacional en derechos de los pueblos indígenas, realizadas conjuntamente por el IIDS y la PUCP.

raquelyf@alertanet.org 
En los países latinoamericanos existe una importante discusión en torno a cuál es la mejor forma de reconocer los derechos indígenas y darle forma jurídica a la principal consecuencia de dicho reconocimiento, cual es, el pluralismo jurídico. Los sistemas políticos nacionales han dado distintas respuestas institucionales ante esta realidad regional; en muchos países estas respuestas han sido constitucionales. En este proceso, el derecho internacional de los derechos humanos (DIDH), por una parte, ha contribuido a que se reconozca una visión amplia del contenido y alcance de los derechos fundamentales de las personas y de los pueblos indígenas. Pero, por otra parte, la aplicación de modelos multiculturales ha generado críticas desde el DIDH, ya que ciertas prácticas culturales o "costumbres" indígenas pueden contravenir derechos no susceptibles de afectación. Para aclarar algunos conceptos y para poder establecer algunas posiciones respecto de este tema, es que sometemos las siguientes preguntas a discusión:

1. Modelos de Estados. Los diversos modelos de Estado no sólo tienen fundamentos distintos, sino que también consecuencias diferentes respecto de su estructura institucional y cultural, ¿cuál es, a su juicio, el modelo de Estado (liberal-social-multicultural plurinacional) que permite resguardar u otorgar un mejor reconocimiento a los derechos indígenas? Y ¿cuáles son las consecuencias de tratar el multiculturalismo bajo este modelo estatal?

2. Modelo institucional. La construcción institucional de un Estado (poderes, funciones, relación entre los poderes, relación con la sociedad civil, entre otros aspectos) es fundamental para llevar a cabo las ideas fundantes de un determinado modelo estatal. En este sentido, se ha discutido sobre la necesidad de replantear la institucionalidad una vez reconocida la multiculturalidad (nuevos poderes, nuevas relaciones entre poderes, redefinición de funciones, nuevas formas de participación). A su juicio, ¿es necesario efectuar ajustes en el modelo institucional o cabe rediseñarlo para dar reconocimiento y garantía a los derechos indígenas?

3. Aporte del DIDH. EI DIDH ha aportado en el reconocimiento y garantía de los derechos indígenas y de aquellos de los pueblos indígenas. A su juicio, ¿de qué forma el DIDH ha sido significativo para el avance en materia de reconocimiento de una perspectiva amplia del contenido y alcance de los derechos humanos de titulares indígenas? ¿Qué rol juega en dicho proceso el reconocimiento de los derechos colectivos?

4. Límites a las prácticas culturales indígenas. Desde una perspectiva de respeto a la dignidad y los derechos humanos consagrados en las constituciones nacionales y los tratados internacionales: ¿es posible y/o justificable imponer límites a las prácticas culturales indígenas o sistemas legales indígenas? 


\section{Modelos de Estado}

Los diversos modelos de Estado no sólo tienen fundamentos distintos, sino que también consecuencias diferentes respecto de su estructura institucional y cultural, ¿cuál es, a su juicio, el modelo de Estado (liberal-social-multicultural plurinacional) que permite resguardar u otorgar un mejor reconocimiento a los derechos indígenas? $\mathrm{Y}_{i}$ cuáles son las consecuencias de tratar el multiculturalismo bajo este modelo estatal?

1. Modelos de Estado

\section{ALEXEI JULIO-ESTRADA}

Desde mi punto de vista la definición constitucional del modelo de Estado, aunque puede tener importancia para el reconocimiento de los derechos de los pueblos indígenas, no es definitorio, porque como es bien sabido desde la famosa clasificación de las Constituciones propuesta por Loewenstein ${ }^{1}$, no hay una necesaria equivalencia entre el texto constitucional y el diseño institucional y político. Ahora bien, al margen de dicha acotación inicial, considero que el diseño constitucional propio de un Estado liberal puede presentar algunas incompatibilidades en cuanto al respeto, garantía y protección de los derechos indígenas, especialmente en tres aspectos: (i) el reconocimiento de derechos especiales a ciertos grupos étnicos podría resultar contrario a la idea de derechos universales; (ii) la titularidad y naturaleza colectiva de los derechos indígenas, en principio opuesta a este modelo estatal que se construye a partir del individuo; y (iii) la idea de jurisdicciones indígenas con un derecho especial porque resulta contraria a la igualdad de todos los ciudadanos en la aplicación de la ley, otro de los pilares en la construcción del Estado liberal. Empero, no considero ninguna de estas limitaciones imposible de superar, pues insisto en que el modelo constitucional puede ser ajustado por prácticas constitucionales e institucionales que sean respetuosas de los derechos de los pueblos indígenas.

Respecto del modelo de Estado social, prima facie, no percibo las contradicciones antes enunciadas, pues aunque no supone el reconocimiento de derechos indígenas tampoco lo excluye. En todo caso, quedaría la cuestión de si debido a las particularidades del diseño institucional de este modelo estatal, que implica una fuerte actividad estatal en defensa de los grupos desaventajados y excluidos, en ciertos casos, este mandato constitucional podría confundirse con políticas de asimilación de los miembros de los pueblos indígenas y tribales para que sean integrados en la sociedad mayoritaria sin tener en cuenta sus rasgos culturales distintivos. Ahora bien, en mi país, Colombia, hay un fuerte reclamo por parte de ciertos grupos étnicos de medidas de acción afirmativa que permitan esa particular integración, sobre todo en materia de educación y empleo, las cuales son identificadas, por regla general, con un Estado social. Por otra parte, este modelo estatal es compatible con la propiedad colectiva propia de algunos pueblos indígenas y tribales. La Constitución colombiana de 1991 acogió el modelo de Estado social en su artículo primero, estableciéndose un reconocimiento concreto a la diversidad étnica y cultural en su artículo séptimo. Colombia, es por lo tanto, un Estado social y multicultural, lo que ha resultado favorable para el reconocimiento, garantía y protección de los derechos de los pueblos indígenas. El texto

\footnotetext{
Loewenstein introduce un criterio de clasificación de las Constituciones que denomina "ontológico", basado en la concordancia de las normas constitucionales con la realidad del proceso de poder. De acuerdo con dicho criterio, las Constituciones pueden ser diferenciadas de acuerdo a su carácter normativo (aquellas en las cuales el proceso de poder se adapta a las normas constitucionales y se somete a ellas), nominal (cuando la Constitución es jurídicamente válida, pero la dinámica del proceso político no se adapta completamente a sus normas) o semántico (cuando la Constitución se limita a formalizar la situación existente de poder político en beneficio de sus actuales detentadores). Ver, LOEWENSTEIN, Karl. Teoría de la Constitución. Barcelona: Ariel, 1986, pp. 216 y ss.
} 
constitucional garantiza los derechos culturales, la participación de los pueblos indígenas en el Congreso mediante circunscripciones especiales, la propiedad colectiva, la etnoeducación y la jurisdicción especial. Ahora bien, el diseño dista de ser perfecto porque en todo caso hay constantes fuentes de fricciones que tienen origen en el mismo texto constitucional, como por ejemplo, en lo que se relaciona con la explotación de los recursos naturales -el subsuelo es propiedad del Estado-.

En cuanto al modelo de Estado plurinacional considero que a pesar de haber sido reconocido en ciertas Constituciones como la de Ecuador y la de Bolivia, aun no se ha construido en la práctica y, a mi juicio, supone particulares problemas de configuración y armonización territorial y política.

\section{JOSÉ ANTONIO RIVERA}

1. Modelos de Estado

Considerando las bases sobre las que se configura, el modelo de Estado plurinacional es el que permite consagrar y resguardar de mejor manera los derechos indígenas, tanto los individuales como los colectivos.

El Estado plurinacional es un modelo de organización político, social, cultural, económico y jurídico basado en la coexistencia de varias naciones o pueblos indígenas originarios bajo una misma Constitución y gobierno estatal; con un reconocimiento a esas naciones y pueblos indígenas de su territorio propio, su régimen económico, su idioma, su sistema jurídico y el derecho de autogobernarse, con competencias administrativas, económicas y culturales.

Ahora bien, las demandas centrales de los pueblos indígenas para el reconocimiento de sus derechos colectivos son: (i) derecho a la autodefinición y a un estatus legal, lo que supone el reclamo de un nuevo estatus para los pueblos indígenas en el marco de una sociedad democrática; (ii) derecho a la tierra y al territorio, lo que significa el reclamo del reconocimiento y la delimitación legal de sus territorios ancestrales; (iii) derecho a la identidad cultural, lo que supone el reclamo del reconocimiento y desarrollo de su propia identidad cultural, incluyendo lenguas, tradiciones y manifestaciones culturales indígenas en general; (iv) derecho a su organización social y su sistema jurídico, lo que significa el reclamo del reconocimiento a sus formas tradicionales de autoridad local, de los mecanismos para la resolución de conflictos, de las prácticas relativas a la herencia y el patrimonio, y de los patrones de uso de la tierra y los recursos comunales; y (v) el derecho a la libre determinación, lo que implica el reclamo del reconocimiento del derecho a contar con un orden político bajo el cual los individuos y los grupos sean capaces de tomar decisiones significativas en asuntos que afectan todas las esferas de su vida.

Si se toma en cuenta que el Estado plurinacional se asienta en la existencia de diferentes naciones o pueblos indígenas originarios con formas de vida y de organización propias, con mecanismos de autorregulación y elección de autoridades a través de normas y procedimientos propios, entre otras, pero bajo el amparo de un solo Estado, se puede afirmar que es el modelo adecuado para un reconocimiento, consagración y protección de los derechos colectivos de los pueblos indígenas que vienen reclamando como parte de su reivindicación.

Sin embargo, cabe señalar que, si bien es cierto que el modelo de Estado plurinacional es el que permite un mejor reconocimiento de los derechos indígenas, no es menos cierto que el tratamiento del multiculturalismo bajo este modelo estatal no está exento de problemas de diverso orden; desde el plano social, político y económico.

En el plano social, la implementación del multiculturalismo se enfrenta a las manifestaciones del racismo aún persistente en aquellos sectores sociales privilegiados o de élite que han sojuzgado a 
los pueblos indígenas. Como sostiene James Anaya²: "no resulta fácil cambiar actitudes mayoritarias recalcitrantes, estructuras sociales y usos jurídicos que han sido hostiles a las culturas indígenas por siglos". En consecuencia, es de vital importancia desplegar acciones para desmontar esas conductas racistas y generar una cultura de convivencia pacífica.

En el plano político, la implementación del multiculturalismo se enfrenta con políticas y prácticas oficiales del Estado que desconocen la nueva realidad y pretenden imponer su visión monocultural, vulnerando los derechos colectivos de los pueblos indígenas ${ }^{3}$.

Finalmente, en el plano económico, la implementación del multiculturalismo se enfrenta a las políticas económicas que tienen su base en la concepción desarrollista de quienes detentan el poder, cuya implementación sacrifica los derechos de los pueblos indígenas.

1. Modelos de Estado

\section{NEUS TORBISCO}

Las demandas de los pueblos indígenas son sumamente heterogéneas y, de hecho, la etiqueta "derechos indígenas" engloba un conjunto de intereses de naturaleza diversa. Por ello, dilucidar el alcance de estos derechos y qué modelo de Estado resulta idóneo para acomodarlos requeriría adoptar un enfoque contextual dirigido a desvelar la clase de reconocimiento público a la que aspiran estos pueblos. Aspectos como la historia de sus relaciones con el Estado, el encaje de sus demandas en un marco constitucional determinado o la situación de mayor o menor concentración territorial de sus miembros son, por tanto, cruciales para emitir un juicio fundado acerca de la magnitud del reto institucional que supone reconocer derechos a los pueblos indígenas. Sin embargo, ciertos elementos comunes en el discurso de estos pueblos permiten trazar las líneas elementales de una respuesta que pasa por distinguir entre dos tipos de intereses cuyo acomodo plantea desafíos de naturaleza distinta en el contexto de los Estados democráticos ${ }^{4}$.

Una primera categoría de demandas se refiere a la adopción de medidas que aseguren que los derechos, intereses y perspectivas de los miembros de los pueblos indígenas, en tanto "sujetos individuales", se tengan en consideración de manera igualitaria en el seno de la sociedad, inclusive en las instituciones políticas. Se trata, en síntesis, de reafirmar y hacer efectivo el derecho a la igualdad de oportunidades y a la no discriminación en el ejercicio de los derechos humanos reconocidos en el preámbulo de la Declaración de las Naciones Unidas sobre los derechos de los pueblos indígenas (DDPI). Diversos artículos de esta declaración desarrollan este enfoque más individualista, que toma en consideración a la persona indígena como sujeto individual ${ }^{5}$. La pretensión última de estas normas es la erradicación de la discriminación en el disfrute de los

2 ANAYA, James. Los Pueblos Indígenas y Estado Multicultural. México: Programa sobre Cooperación de Derechos Humanos, Librería, 2006, p. 4. [en línea] <http://portal.sre.gob.mx/pcdh/libreria/libro10/03james.pdf> [consulta: 15 enero 2013].

3 Un ejemplo de ello es el caso de la adopción de medidas legislativas y administrativas del Gobierno del Estado Plurinacional de Bolivia, que afectan los derechos colectivos de los Pueblos Indígenas Originarios Amazónicos Yuracarés, Trinitarios y Chimanes, sin haberse realizado la consulta previa mediante procedimientos apropiados y, en particular, a través de sus instituciones, como está expresamente consagrado por el art. 30.II.17 de la Constitución, poniendo con esa decisión en amenaza los derechos colectivos a existir libremente, a la libre determinación y territorialidad, a vivir en un medio ambiente sano, con manejo y aprovechamiento adecuado de los ecosistemas.

4 El reconocimiento de derechos indígenas y de los derechos humanos en general, en contextos no democráticos plantea retos distintos que, en principio, dejaré al margen en las reflexiones expuestas en este simposio.

5 Véanse, por ejemplo, los artículos 1, 2 y 7. 
derechos humanos básicos (y en el acceso, en condiciones de igualdad, a oportunidades y bienes como el empleo, la salud o la educación) que sufren los individuos por el hecho de ser indígenas.

La identidad indígena emerge, en este contexto, como factor clave para comprender las fuentes de desigualdad, opresión y pobreza que afectan de manera desproporcionada a estos grupos en prácticamente todas las regiones del planeta ${ }^{6}$. Ahora bien, idéntica problemática se plantea respecto de otros grupos sociales minoritarios cuyos miembros sufren desventajas o discriminación asociados a sus identidades. El caso de las mujeres, de las minorías raciales e incluso de los inmigrantes ofrecen analogías ilustrativas ${ }^{7}$.

Por supuesto, ello no significa que nos encontremos ante dilemas de fácil solución. Tomemos, por ejemplo, el caso de la desigualdad de género. Para los críticos del Estado liberal en el sentido más clásico, la persistencia de la discriminación hacia la mujer ofrece clara evidencia del fracaso de los mecanismos de protección de derechos típicos de este modelo (basados, sobre todo, en la presunción de igualdad de oportunidades y en la primacía de la intervención judicial para el caso de violaciones de los mismos). Desde esta perspectiva, que comparten feministas y liberales igualitarios, el Estado debería asumir un papel mucho más proactivo en la transformación institucional con el fin de erradicar estructuras y patrones que contribuyen a reproducir la desigualdad estructural de ciertos grupos ${ }^{8}$.

Salvando las distancias, el núcleo de la discusión esbozada es aplicable al problema de los derechos indígenas, entendidos en este primer sentido más individualista. Mi opinión personal es que los Estados liberales democráticos comprometidos con políticas sociales fuertes -los denominados "Estados sociales" - se hallan mejor posicionados para promover los derechos humanos y el desarrollo de la población indígena. Lo prioritario, por tanto, sería superar la visión liberal más minimalista del Estado asociada a una concepción negativa de los derechos.

Ahora bien, nótese que esta primera categoría de derechos no requiere adoptar un modelo de Estado multicultural en sentido estricto -esto es, un Estado que reconoce la relevancia intrínseca de la diversidad cultural, sin reducir este fenómeno a su dimensión socioeconómica-. Tampoco exige cuestionar la teoría individualista de los derechos humanos. La identidad indígena adquiere relevancia como factor "explicativo", si se quiere, antes que normativo: permite identificar los factores condicionantes de la desigualdad que sufren los miembros de un determinado grupo social. Pero el objetivo último de las políticas antidiscriminatorias es lograr una ciudadanía homogénea en la que la identidad etnocultural sea irrelevante en la esfera pública ${ }^{9}$.

La segunda categoría de derechos indígenas, en cambio, presenta un desafío más radical. Se trata de derechos colectivos cuya titularidad, en principio, se atribuye al grupo como tal, más que a sus miembros individualmente considerados. De nuevo, la DDPI contiene numerosas disposiciones ilustrativas de esta diferencia: el derecho a la libre determinación, que se atribuye

6 Pese a los innegables avances en el reconocimiento de los derechos de los pueblos indígenas, estudios recientes del Banco Mundial corroboran la extrema precariedad en las condiciones de vida de los ciudadanos indígenas.

7 En lo que sigue, empleo el término "minoría" para referirme a grupos desaventajados o no dominantes en la esfera pública, más que en el sentido estrictamente numérico.

8 Ciertamente, aún entre quienes suscriben esta idea existen discrepancias importantes acerca de cuáles deberían ser los límites de la interferencia estatal en la autonomía privada. Por ejemplo, feministas y liberales igualitaristas no siempre están de acuerdo acerca de si la acción afirmativa es un instrumento justificable como parte de una política de género que promueva el acceso pleno de la mujer a la función pública.

9 De ahí que medidas como la acción afirmativa se conciban siempre de forma transitoria; es decir, atribuyen un estatus diferenciado de manera temporal, en tanto que la igualdad no sea real y efectiva. 
directamente a los pueblos indígenas (artículo 3); también el derecho al autogobierno (artículo 4), o el derecho a las tierras, territorios y recursos que tradicionalmente han poseído, ocupado o utilizado (artículo 26.1). La tercera cuestión me permitirá abundar con mayor detalle en la noción de derechos colectivos. Lo relevante, sin embargo, es resaltar el peso normativo que adquiere la dimensión colectiva de la identidad indígena en esta categoría de derechos. Se trata, sobre todo, de garantizar intereses compartidos entre los miembros de un grupo en bienes de naturaleza intrínsecamente colectiva. De ahí que su incorporación al sistema jurídico-político requiera algo más que un giro hacia un modelo de Estado que permita erradicar la discriminación socioeconómica de los individuos indígenas; exige, asimismo, abrazar lo que el filósofo canadiense Charles Taylor denomina una "política del reconocimiento"10 hacia sus pueblos, en tanto que sujetos colectivos. Esta política pretende dar cuenta de la multiculturalidad en tanto que rasgo central de la comunidad política y, en este sentido, requiere transformar la visión típicamente uniforme de la ciudadanía y de los derechos.

1. Modelos de Estado

\section{ARESIO VALIENTE}

Para que el Estado moderno tenga realmente una participación real y efectiva de los pueblos indígenas, necesitaría la reestructuración de sus instituciones. Esta reestructuración tiene que ser integral.

Uno de los elementos del Estado es la población, la cual en la actualidad no reconoce como uno de sus componentes a los pueblos indígenas, que cuentan con su propia cultura. Debe haber una política que transforme también las estructuras sociales, las que deben buscar como uno de sus objetivos reconocer que el Estado es multicultural.

Se debe celebrar un nuevo contrato social entre los Estados y los pueblos indígenas, con el fin de que éstos sean partícipes de la reestructuración de las instituciones estatales, con el objetivo de que se respeten sus derechos fundamentales mediante políticas públicas.

El Estado multicultural no solamente debe significar un reconocimiento a nivel constitucional, sino que debe ser parte de las políticas públicas y un elemento integral en la formación de la sociedad actual. También deben crearse leyes que hagan realidad este Estado moderno multicultural, lo cual implica no sólo que los pueblos indígenas ejerzan sus derechos, sino también que el resto de la sociedad respete y valore la cultura indígena.

El futuro del Estado o de los Estados es el reconocimiento real y efectivo de que su sociedad está cimentada en diferentes culturas y, por ende, es multicultural. Este reconocimiento es la base de la convivencia pacífica entre diferentes culturas que existen en él.

\section{RAQUEL Z. YRIGOYEN*}

1. Modelos de Estado

La relación entre modelo de Estado y pueblos indígenas remite no sólo a la protección de los derechos indígenas sino que también a la configuración misma del Estado, esto es, quiénes lo han constituido, quiénes lo conforman y quiénes ejercen

10 TAYLOR, Charles. "The Politics of Recognition". En: GUTMAN Amy (ed.). Multiculturalism: examining the Politics of Recognition. Princeton, New Jersey: Princeton University Press, 1994.

* La autora contó con la colaboración de Carlos J. Elguera Alvarez, asistente de investigación en el Instituto Internacional de Derecho y Sociedad-IIDS / International Institute on Law and Society-IILS. 
poder. Una breve mirada histórica nos permite identificar los hitos o modelos de conformación estatal y cuál es la participación de los pueblos indígenas en los distintos modelos de Estado y las atribuciones y derechos que tienen los mismos en cada uno de ellos ${ }^{11}$.

El hecho colonial colocó a los pueblos originarios en una posición subordinada. Sus territorios y recursos fueron objeto de expropiación por terceros, su mano de obra fue explotada y su destino alienado, lo que se institucionalizó en el derecho bajo la figura de la tutela indígena.

La independencia política de las colonias americanas respecto de las metrópolis no significó el fin de la subordinación indígena sino nuevas formas de sujeción indígena bajo la batuta de las élites criollas latinoamericanas, en el marco del horizonte del constitucionalismo liberal. En el siglo XIX, los Estados se organizaron bajo el modelo del Estado-nación monocultural, el principio de una sola ley para todos los ciudadanos (monismo jurídico) y un modelo de ciudadanía censitaria, que sólo reconocía derechos ciudadanos a hombres blancos, propietarios e ilustrados, sin considerar a los pueblos originarios, afrodescendientes, mujeres y trabajadores dependientes. La exclusión y subordinación de los pueblos originarios se hizo a través de tres técnicas constitucionales: (i) disolver las protecciones coloniales a las tierras colectivas de los pueblos de indios, a las autoridades y al fuero indígena, bajo el discurso de asimilar a los indios a ciudadanos en tanto "dejaran de ser indios" y se convirtieran en propietarios individuales; (ii) expandir el Estado y la frontera agrícola hacia territorios no colonizados habitados por "salvajes", a quienes había que conducir a la civilización y cristianización; y (iii) incorporar territorios ocupados por naciones de indios "bárbaros", con quienes en el periodo colonial las coronas firmaron tratados en momentos de guerra. En algunos Estados se utilizaron estas técnicas incluso sin previsión constitucional, sino meramente legal.

El horizonte del constitucionalismo social, inaugurado por la Constitución de México de 1917, permitió cuestionar el constitucionalismo asimilacionista e individualista del siglo XIX mediante el reconocimiento de sujetos colectivos, derechos sociales y la ampliación de las bases de la ciudadanía. Ello permitió el reconocimiento de comunidades indígenas y sus derechos colectivos a la tierra, así como especificidades culturales, dentro del marco de un indigenismo integracionista. Este modelo buscaba integrar a los indígenas al Estado y al mercado, con sus especificidades culturales, pero sin romper la identidad Estado-nación ni el monismo jurídico. Asimismo, el Estado mantuvo la potestad de definir el desarrollo económico y los límites de la integración y del reconocimiento del derecho consuetudinario indígena. El Estado, como tutor, seguía definiendo lo que "era bueno" para los indígenas.

Monoculturalidad, monismo jurídico y modelo tutelar indígena recién son puestos en cuestión a partir de los 80 del siglo XX, en el marco del horizonte del constitucionalismo pluralista. Los cambios en el derecho internacional y constitucional han permitido el reconocimiento de la diversidad cultural y nuevos derechos indígenas, así como la participación de los pueblos indígenas como sujetos constituyentes de los nuevos Estados. Ello, a su vez, ha posibilitado cambiar la configuración del modelo de Estado, nación y derecho. El constitucionalismo multicultural (1982-1988) constituye el primer ciclo del horizonte del constitucionalismo pluralista, y da apertura al reconocimiento del derecho a la diversidad cultural. El constitucionalismo pluricultural (1989-2005), luego de la adopción del Convenio 169 de la OIT sobre pueblos indígenas y tribales

11 Ver, YRIGOYEN, Raquel. "El Horizonte del constitucionalismo pluralista: del multiculturalismo a la descolonización". En: RODRÍGUEZ GARAVITO, César (Coord.). El derecho en América Latina. Un mapa para el pensamiento jurídico del siglo XXI. Buenos Aires: Siglo Veintiuno Editores, 2011, pp. 139-159. 
(Convenio 169 de la OIT), reconoce una más amplia gama de derechos colectivos a los pueblos indígenas y el pluralismo jurídico. Finalmente, el constitucionalismo plurinacional (2006-2009), luego de la aprobación de la Declaración de Naciones Unidas sobre los derechos de los pueblos indígenas, cuestiona la herencia colonial y republicana de la exclusión de las naciones originarias y afrodescendientes, y define al Estado como un pacto de tales naciones, esto es, como un Estado plurinacional que reconoce nuevos derechos para los indígenas y nuevos derechos aportados por las culturas indígenas (como los derechos de la pachamama, etcétera).

\section{Modelo institucional}

La construcción institucional de un Estado (poderes, funciones, relación entre los poderes, relación con la sociedad civil, entre otros aspectos) es fundamental para llevar a cabo las ideas fundantes de un determinado modelo estatal. En este sentido, se ha discutido sobre la necesidad de replantear la institucionalidad una vez reconocida la multiculturalidad (nuevos poderes, nuevas relaciones entre poderes, redefinición de funciones, nuevas formas de participación). A su juicio, ¿es necesario efectuar ajustes en el modelo institucional o cabe rediseñarlo para dar reconocimiento y garantía a los derechos indígenas?

2. Modelo institucional

\section{ALEXEI JULIO-ESTRADA}

Mi respuesta a esta pregunta va a estar guiada por la experiencia propia del caso colombiano.

Desde esta perspectiva lo primero que se constata es que el diseño institucional ha tardado en adaptarse al cambio constitucional que implicó la Constitución de 1991, la cual reconoce la diversidad étnica y cultural y señala un conjunto de derechos y garantías de los pueblos indígenas y tribales. Por ejemplo, hasta la fecha no se ha expedido la ley que permita la coordinación entre la jurisdicción especial indígena y otras jurisdicciones, tampoco los territorios indígenas han podido transformarse en entidades territoriales, las leyes sólo han regulado de manera parcial lo relacionado con la etnoeducación y ha habido particulares dificultades en la conformación de instancias de carácter nacional para la concertación y consulta de políticas públicas con los pueblos indígenas y las comunidades afro colombianas. No obstante, todos estos inconvenientes han sido superados a partir del entendimiento de que la Constitución tiene eficacia normativa y que sus preceptos pueden ser aplicados por las autoridades jurisdiccionales, especialmente por la Corte Constitucional, de tal manera que mediante una serie de precedentes se ha determinado el alcance y contenido de los preceptos que establecen los derechos indígenas, algunos de los cuales han sido recogidos posteriormente por la legislación. Estos precedentes jurisprudenciales no implicaron la creación de instituciones nuevas, sino simplemente la adaptación de las ya existentes al nuevo modelo de Estado multicultural.

Esta breve descripción permite arribar a algunas conclusiones: más que un completo cambio institucional, lo que se requiere son ciertos ajustes que permitan en la práctica el respeto, garantía y protección de los derechos de los pueblos indígenas. Y, en segundo lugar, resulta necesario tomarse los derechos indígenas en serio, pues aun sin un marco normativo e institucional es posible su reconocimiento y garantía. 
2. Modelo institucional

\section{JOSÉ ANTONIO RIVERA}

Para garantizar el reconocimiento y adecuada protección de los derechos indígenas en el modelo de Estado plurinacional, es necesario replantear el modelo institucional, porque, como sostiene Boaventura de Sousa Santos "la plurinacionalidad obliga, obviamente, a refundar el Estado moderno, porque el Estado moderno [...] es un Estado que tiene una sola nación, y en este momento hay que combinar diferentes conceptos de nación dentro de un mismo Estado" 12 .

El Estado plurinacional debe configurarse sobre la base del pluralismo político, económico, cultural, jurídico y lingüístico; fundado en la interculturalidad y el poscolonialismo.

En el plano político, el ejercicio del poder político en el Estado plurinacional debe configurarse sobre la base de la distribución territorial del poder político, como sostiene Boaventura de Sousa Santos "las sociedades plurinacionales tienen que ser sociedades descentralizadas, lo que no significa que el Estado no sea fuerte. El Estado tiene que ser fuerte, pero tiene que ser fuerte democráticamente para aguantar los niveles de descentralización"13. El modelo de Estado plurinacional supone la distribución territorial del poder político, otorgando a los pueblos indígenas, a partir del reconocimiento de su derecho a la autodeterminación, la capacidad de decisión sobre su propia organización, el control y gestión de los recursos naturales y, consecuentemente, su propio desarrollo económico y social.

En coherencia con lo anterior, en el marco de un nuevo concepto de territorialidad, debe adoptarse una nueva organización territorial del Estado, reconociendo a los territorios de los pueblos indígenas la calidad de entidades territoriales con autonomía, de manera que el Estado adopte un modelo de descentralización política, económica y administrativa.

Con relación al régimen de gobierno, el Estado plurinacional debe adoptar una democracia intercultural que, a decir de Boaventura De Sousa Santos, tiene las siguientes características: debe tener diferentes formas de deliberación democrática; debe tener formas de acción afirmativa y discriminación positiva expresada en un doble criterio de representación, que se manifieste en un criterio cuantitativo del voto y un criterio cualitativo de consenso o sistema de rotación ${ }^{14}$.

El régimen jurídico del Estado debe configurarse sobre la base del pluralismo jurídico, lo que supone la coexistencia del sistema jurídico estatal con los sistemas jurídicos de los pueblos indígenas. El Estado debe reconocer y garantizar el sistema jurídico que tienen cada uno de los pueblos indígenas, entendiéndose por este sistema de principios, valores y reglas consuetudinarias y la potestad de impartir justicia a través de la jurisdicción comunitaria o indígena, la que deberá gozar de igual jerarquía que la jurisdicción estatal.

La estructura económica del Estado debe ser plural, lo que implica la coexistencia de diferentes formas de organización económica: la estatal y la comunitaria de los pueblos indígenas.

En suma, resulta necesario adoptar un nuevo modelo institucional que supone la modificación de los órganos de poder, determinar nuevas formas de relación entre estos órganos, redefinición de las funciones de los órganos estatales; y crear nuevas formas de participación ciudadana.

\footnotetext{
12 DE SOUSA SANTOS, Boaventura. La Reinvención del Estado y el Estado Plurinacional. Santa Cruz: Alianza Interinstitucional CENDA, CEJIS, CEDIB, 2007, p. 18.

13 Ibídem, p. 30.

14 Ibídem, p. 31.
} 
2. Modelo institucional

\section{NEUS TORBISCO}

Por las razones indicadas, el reconocimiento de derechos colectivos a los pueblos indígenas afectará necesariamente la auto comprensión profunda del Estado en tanto Estado multicultural -i.e. compuesto por distintas comunidades igualmente valiosas que gozan del grado necesario de autonomía política para desarrollar sus propias instituciones culturales-. Plasmar esta mutación requiere ir más allá de un simple reajuste de poderes o funciones estatales. En general, es preciso iniciar un proceso dirigido a reconfigurar e incluso refundar el Estado, replanteando el diseño institucional con el fin de asegurar la visibilidad de los asuntos y de la perspectiva indígena. Una efectiva desvinculación de los poderes públicos del control históricamente ejercido por la mayoría cultural dominante podría asegurarse adoptando mecanismos de representación especial (lo que Will Kymlicka denomina special group-representation rights ${ }^{15}$ ) en las instituciones más relevantes, como el parlamento. El objetivo no es únicamente que los intereses de los pueblos indígenas contribuyan a definir el bien común, sino también reflejar el hecho de que el poder es compartido.

Por otro lado, el reconocimiento de un grado significativo de autogobierno indígena tal vez requiera abrir un proceso de reforma constitucional para acomodar posibles pactos entre el Estado y los pueblos indígenas, difícilmente planteables en el marco del modelo de Estado-nación unitario sustentado en un ideal de ciudadanía homogénea. Este punto es, a mi juicio, crucial. La visión homogénea del demos, que mantiene con el Estado una relación unidireccional y simétrica de carácter directo, resulta incongruente con el reconocimiento de autoridad y autonomía a grupos intermedios -i.e., comunidades culturales que adquieren estatus político y asumen cierto autogobierno-. El pluralismo inherente al Estado multicultural debe traducirse, entonces, en la aceptación de lo que Iris $M$. Young denomina un modelo de ciudadanía diferenciada ${ }^{16}$, que refleje el hecho de que los individuos tienen, de un lado, derechos individuales derivados de su condición general de ciudadanos (y como seres humanos, de manera más genérica) y, de otro, derechos derivados de su pertenencia a grupos identitarios diferenciados (en este caso, de su estatus o condición de miembros de una comunidad o pueblo indígena). Reconocer esta doble pertenencia (o identidad dual) inevitablemente afectará a la atribución, interpretación y ejercicio de los derechos, generando asimetrías que sólo cabe comprender desde el pluralismo jurídico.

Por último, no debería confundirse el modelo de Estado multicultural que he tratado de delinear con un planteamiento alternativo basado en la tolerancia como fundamento de los derechos indígenas. La idea es que no es necesario atribuir derechos a los grupos, sino que basta con que el Estado practique una política de tolerancia que se traduzca en la deferencia (o no interferencia) respecto de los asuntos indígenas. Pero, a mi juicio, esta versión más débil del multiculturalismo fracasa. Y ello porque, en el fondo, el lenguaje de la tolerancia no es compatible con el genuino reconocimiento de derechos humanos. Asumimos que quien tolera tiene discreción y que, por tanto, podría dejar de tolerar. En este sentido, se trata de un enfoque que reduce los derechos indígenas a meros permisos sin llegar a cuestionar la legitimidad y el papel dominante de la autoridad estatal. Es más, las normas, prácticas e instituciones indígenas corren el peligro de quedar relegadas a un territorio al margen de la legalidad oficial.

15 KYMLICKA, Will. Multicultural Citizenship. A Liberal Theory of Minority Rights. Oxford: Clarendon Press, 1995.

16 YOUNG, Iris. "Polity and Group Difference: A Critique of the Ideal of Universal Citizenship". En: Ethics 99 (2), 1989 , pp. 250-274. 
En contraste con esta imagen, una genuina reconstrucción del Estado sobre cimientos multiculturales -esto es, un Estado multicultural en sentido fuerte- conlleva, como he dicho, el replanteamiento de los poderes institucionales, de tal manera que dejen de considerarse patrimonio (o reflejo) de la cultura dominante. Acomodar los derechos indígenas requiere, por consiguiente, reconocer el estatus distintivo de los pueblos indígenas, en tanto sujetos políticos capaces de autogobernarse, y no meramente en tanto grupo que debe ser "objeto" de regulación o de tolerancia.

2. Modelo institucional

\section{ARESIO VALIENTE}

No cabe duda de que para que exista real participación de los pueblos indígenas, es necesaria la reestructuración o reconstrucción del Estado, la que debe reconocer y respetar las instituciones políticas de los pueblos indígenas.

Una de las instituciones que el Estado debe reconocer es la de la autonomía de los pueblos indígenas. La figura de la autonomía indígena es una de las formas de descentralización del Estado, para que los mismos pueblos indígenas puedan determinar su desarrollo social, económico, político y espiritual.

Hoy se ha demostrado que el modelo de centralización del Estado no es viable para el desarrollo de las regiones; las propuestas que los pueblos indígenas han planteado sobre la descentralización del Estado, a través de la figura de autonomía son claves para que el desarrollo llegue realmente a los territorios indígenas, respetando la cosmovisión indígena y sobre todo los principios que practican ellos en su relación con la naturaleza.

En la reestructuración del Estado deben participar en forma efectiva, activa y paritaria los pueblos indígenas. La reestructuración del Estado debe buscar la suscripción del nuevo pacto social entre diferentes sectores de la sociedad, el cual debe respetar y reconocer los derechos de todos los grupos sociales que conviven en un mismo Estado.

2. Modelo institucional

\section{RAQUEL Z. YRIGOYEN}

La participación de los pueblos indígenas como sujetos constituyentes y partícipes de atribuciones en los Estados no sólo requiere "ajustes", sino nuevos diseños institucionales en cuya elaboración hayan participado dichos pueblos.

Las reformas constitucionales más importantes que se han dado en los últimos tres lustros han impactado en la definición misma del modelo de Estado y reconfiguran la relación jurídica entre los Estados y los pueblos indígenas. Estas reformas se han dado bajo el horizonte del Convenio 169 de la OIT. Como ejemplo, todos los países andinos, excepto Chile, han cambiado su Constitución (Colombia en 1991, Perú en 1993, Bolivia en 1994 y 2007, Ecuador en 1998 y 2008, y Venezuela en 1999) y han incorporado algunos elementos del Convenio 169 de la OIT. Entre tales reformas cabe destacar las que siguen ${ }^{17}$ :

17 Ver, YRIGOYEN, Raquel. "A los veinte años del Convenio 169 de la OIT: Balance y retos de implementación de los derechos de los pueblos indígenas en Latinoamérica". En: YRIGOYEN, Raquel (Coord.). Pueblos Indígenas, Constituciones y Reformas Políticas en América Latina. Lima: ILSA, INESC e IIDS, 2010, pp.34-36; e YRIGOYEN, Raquel. "Hitos del reconocimiento del pluralismo jurídico y el derecho indígena en las políticas indigenistas y el constitucionalismo andino". En: BERRAONDO, Mikel (Coord.) Pueblos indigenas y derechos humanos. Bilbao: Universidad de Deusto, pp. 537-567. 
(i) El reconocimiento del carácter pluricultural del Estado/Nación/República, y el derecho a la identidad cultural, individual y colectiva. Ello permite superar la idea del Estado-nación monocultural y monolingüe.

(ii) El reconocimiento de la igual dignidad de las culturas, que rompe la supremacía institucional de la cultura occidental sobre las demás.

(iii) El carácter de sujetos políticos de los pueblos y comunidades indígenas y campesinas. Los pueblos indígenas tienen derecho al control de sus instituciones políticas, culturales y sociales y su desarrollo económico. Ello permite superar el tratamiento tutelar de dichos pueblos, como objeto de políticas que dictan terceros.

(iv) El reconocimiento de diversas formas de participación, consulta y representación directa de pueblos indígenas, campesinos y afro descendientes. Ello supera la idea de que sólo los funcionarios públicos representan y pueden formar la voluntad popular.

(v) El reconocimiento del derecho (consuetudinario) indígena y la jurisdicción especial. Ello supone una forma de pluralismo jurídico interno. Todos los países andinos, a excepción de Chile, han incorporado en la Constitución alguna fórmula de pluralismo legal reconociendo autoridades indígenas o campesinas, funciones de justicia o jurisdiccionales, y el derecho indígena o sus propias normas y procedimientos.

(vi) Junto con ello, el reconocimiento de un conjunto de derechos relativos a la tierra, las formas organizativas colectivas, educación bilingüe intercultural, oficialización de idiomas indígenas, etcétera.

Cabe advertir que las reformas constitucionales no necesariamente se han implementado. Las reformas suponen rupturas paradigmáticas respecto del modelo de Estado y las relaciones entre Estados y pueblos originarios, pero su efectividad depende de cambios institucionales cuyo nivel de implementación varía grandemente entre los Estados de la región.

\section{Aporte del DIDH}

EI DIDH ha aportado en el reconocimiento y garantía de los derechos indígenas y de aquellos de los pueblos indígenas. A su juicio, ¿de qué forma el DIDH ha sido significativo para el avance en materia de reconocimiento de una perspectiva amplia del contenido y alcance de los derechos humanos de titulares indígenas? ¿Qué rol juega en dicho proceso el reconocimiento de los derechos colectivos?

3. Aporte del DIDH de la OIT de 1989, que sin duda ha sido el instrumento marco empleado por muchas jurisdicciones nacionales para definir las obligaciones estatales de respeto, garantía y protección de los derechos de los pueblos indígenas. Particularmente, en lo que hace referencia al derecho a la consulta previa, este tratado ha revestido especial importancia en el caso colombiano, pues ha permitido extender sus alcances en virtud de una interpretación amplia defendida por la Corte Constitucional, de tal manera que todas las decisiones adoptadas por las autoridades públicas 
-incluso las reformas constitucionales- que afecten directamente a las comunidades indígenas y afro colombianas deben ser sometidas a consulta ${ }^{18}$. Asimismo, la DDPI ${ }^{19}$ cobra cada vez mayor importancia y en forma creciente es empleada por las jurisdicciones nacionales para determinar el alcance de los derechos de los pueblos indígenas, aunque se siga discutiendo su fuerza vinculante. Igualmente, ha sido relevante la jurisprudencia de la Corte Interamericana de Derechos Humanos (Corte IDH), que en sus sentencias (por ejemplo la del caso Saramaka vs. Surinam ${ }^{20}$ ) ha defendido una postura interpretativa de los instrumentos internacionales de derechos humanos (especialmente de la Convención Americana de Derechos Humanos) bastante amplia en lo relativo a los derechos de los pueblos indígenas.

Por otra parte, tanto el Convenio 169 de la OIT, como la DDPI y la jurisprudencia de la Corte IDH han reconocido a las comunidades indígenas como titulares de derechos colectivos; sin embargo, estos derechos han sido tratados de distinta manera por las jurisdicciones nacionales. En el caso colombiano, por ejemplo, la jurisprudencia ha entendido que las comunidades indígenas son un titular colectivo de derechos y tales derechos - la propiedad colectiva, el derecho a la consulta, entre otros- son tratados como derechos fundamentales de carácter colectivo, que pueden ser protegidos mediante los mecanismos internos inicialmente previstos para la protección individual de esta categoría de derechos, como la acción de tutela.

3. Aporte del DIDH

\section{JOSÉ ANTONIO RIVERA}

El DIDH ha tenido un significativo aporte para el avance en materia de reconocimiento de una perspectiva amplia del contenido y alcance de los derechos humanos de titulares indígenas.

Ese proceso se ha desarrollado en dos ámbitos. El primero, referido a los derechos humanos de los indígenas en cuanto persona individual. El segundo, referido a los derechos colectivos de los pueblos indígenas en cuanto comunidad.

En el ámbito de los derechos humanos de los indígenas en cuanto persona individual, el DIDH se ha caracterizado por el proceso de positivización de los derechos humanos, mediante la adopción de declaraciones, tratados, pactos y convenciones internacionales, en los que además de crear un catálogo de derechos, se han constituido obligaciones negativas y positivas para los Estados partes, a objeto de que adopten las medidas legislativas, administrativas y jurisdiccionales necesarias para generar las condiciones de goce pleno. Adicionalmente, se ha producido el proceso de judicialización de los derechos humanos, con la creación de organismos internacionales especializados encargados de la promoción, defensa y protección de los derechos humanos.

En el ámbito referido a los derechos colectivos de los pueblos indígenas en cuanto comunidad, cabe destacar que el DIDH, si bien no con la misma intensidad que en el ámbito individual, ha contribuido y contribuye significativamente a su reconocimiento y resguardo.

18 Corte Constitucional de Colombia. Sentencia C-702 de 6 de septiembre de 2010 y sentencia C-366 de 11 de mayo de 2011.

19 ONU. Declaración de las Naciones Unidas sobre los Derechos de los Pueblos Indígenas. Adoptada el 13 de septiembre de 2007.

20 Corte IDH. Caso del Pueblo Saramaka. vs. Surinam. Excepciones Preliminares, Fondo, Reparaciones y Costas. Sentencia de 28 de noviembre de 2007. Serie C No. 172. 
En la primera fase del proceso de positivización, destaca el artículo 1 del Pacto Internacional de Derechos Civiles y Políticos (PIDCP) ${ }^{21}$, que consagra el derecho a la autodeterminación de los pueblos, norma que ha sido invocada en reiteradas ocasiones por los pueblos indígenas, como base de sus reclamaciones; y el Comité de Derechos Humanos de las Naciones Unidas (ONU) que se encarga de labores de supervisión del Pacto, ha resuelto a favor de su aplicación en beneficio de los pueblos indígenas.

En una segunda fase, algo destacable en el DIDH fue la Resolución de 1971, adoptada por el Consejo Económico y Social de la ONU, que autorizó a la Subcomisión para la Prevención de la Discriminación y Protección de las Minorías de Naciones Unidas ${ }^{22}$, la realización de un estudio sobre "El Problema de la discriminación contra las poblaciones indígenas".

Como parte del proceso de positivización corresponde destacar la adopción del Convenio № 169 de la OIT, el que reconoce a los pueblos indígenas sus derechos colectivos como tales, y ya no como derechos de personas individuales.

Finalmente, cabe destacar la DDPI que fue adoptada el 13 de septiembre de $2007^{23}$. La Declaración establece un marco universal de estándares mínimos para la supervivencia, dignidad, bienestar y derechos de los pueblos indígenas del mundo; consagra en específico su derecho a la libre determinación; aborda, entre otras temáticas, los derechos individuales y colectivos.

En el ámbito de los organismos internacionales destaca la labor del sistema interamericano en la afirmación de los derechos de los pueblos indígenas. Ello a partir de una adecuada interpretación de las normas del DIDH, especialmente de la Convención Americana sobre Derechos Humanos $(\mathrm{CADH})$, adoptando determinaciones de protección en las que han establecido precedentes asumidos por los Tribunales Constitucionales de los Estados, como es el caso de Bolivia ${ }^{24}$ y Ecuador ${ }^{25}$.

Esos procesos que se han desarrollado en el DIDH a lo largo de la segunda mitad del siglo XX, han tenido un significativo aporte para el reconocimiento, por parte de los Estados, de los derechos fundamentales con contenidos y alcances amplios en su derecho interno. En las últimas décadas

21 ONU. Pacto Internacional de Derechos Civiles y Políticos. Adoptado el 16 de diciembre de 1966.

22 Actualmente se denomina Subcomisión para la Promoción y Protección de los Derechos Humanos. Ver [en línea] <http:// www2.ohchr.org/spanish/bodies/subcom/index.htm> [consulta: 23 enero 2013].

23 ONU. Declaración de las Naciones Unidas sobre los Derechos de los Pueblos Indígenas. Resolución aprobada por la Asamblea General. Sesión plenaria 13 de septiembre de 2007.

24 El artículo 30.II de la Constitución promulgada el 7 de febrero de 2009 consagra, entre otros, los siguientes derechos colectivos de las Naciones y Pueblos Indígenas Originarios Campesinos: a existir libremente; a su identidad cultural, creencia religiosa, espiritualidades, prácticas y costumbres, y a su propia cosmovisión; a la libre determinación y territorialidad; a que sus instituciones sean parte de la estructura general del Estado; a la titulación colectiva de tierras y territorios; a la propiedad intelectual colectiva de sus saberes, ciencias y conocimientos; al ejercicio de sus sistemas políticos, jurídicos y económicos acorde a su cosmovisión; a ser consultados mediante procedimientos apropiados, y en particular a través de sus instituciones, cada vez que se prevean medidas legislativas o administrativas susceptibles de afectarles; a la participación en los beneficios de la explotación de los recursos naturales en sus territorios; a la gestión territorial indígena autónoma, y al uso y aprovechamiento exclusivo de los recursos naturales renovables; y a la participación en los órganos e instituciones del Estado.

25 La Constitución de 2008, en su artículo 57, en un extenso catálogo, consagra los derechos de las comunas, comunidades, pueblos y nacionalidades indígenas, entre otros, los siguientes: mantener, desarrollar y fortalecer libremente su identidad, sentido de pertenencia, tradiciones ancestrales y formas de organización social; a conservar la propiedad imprescriptible de sus tierras comunitarias; a la consulta previa, libre e informada, dentro de un plazo razonable, sobre planes y programas de prospección, explotación y comercialización de recursos no renovables que se encuentren en sus tierras y que puedan afectarles ambiental o culturalmente; a conservar y promover sus prácticas de manejo de la biodiversidad y de su entorno natural; a no ser desplazados de sus tierras ancestrales; a ser consultados antes de la adopción de una medida legislativa que pueda afectar cualquiera de sus derechos colectivos. 
muchos Estados, principalmente latinoamericanos han encarado reformas constitucionales incorporando los derechos colectivos de los pueblos indígenas y han previsto sistemas de protección jurisdiccional y administrativos de los derechos humanos.

\section{Aporte del DIDH} derechos humanos es, de por sí, trascendente, por cuanto confiere legitimidad moral a las reivindicaciones históricas que unifican el movimiento indígena. Como defendió el ilustre filósofo del derecho Ronald Dworkin, el reino de los derechos confiere una carta de triunfo del individuo (especialmente de los más débiles) frente al poder del Estado, a menudo en manos de mayorías que tienden a menospreciar los intereses de las minorías ${ }^{26}$. Este argumento adquiere mayor trascendencia si cabe cuando el propio derecho internacional reconoce explícitamente los derechos indígenas como derechos humanos. Es precisamente la positivización de este reconocimiento que permite enfatizar los límites a la discrecionalidad estatal a la hora de concebir las relaciones con "sus" pueblos indígenas como si de un asunto exclusivamente doméstico se tratase. En este sentido, si pretenden presentarse ante la comunidad internacional como valedores de los derechos humanos, los Estados en cuyos territorios habitan pueblos indígenas no tienen otra alternativa que asumir el reto de incorporar a sus sistemas jurídico-políticos estos derechos, con independencia de la complejidad que suponga este proceso.

Por otro lado, los avances en el reconocimiento de derechos humanos indígenas han contribuido decisivamente a la integración de un conjunto de identidades plurales desarrolladas en contextos diversos y cambiantes. Así, pueblos etnológica y culturalmente tan diferentes como los Saami en Finlandia, los Lahu en el Sudeste Asiático, los Inuit en Canadá o los Mapuche en Chile se han unido en torno a una identidad que cada vez se percibe más como primordialmente política, al englobar un propósito común: alcanzar lo que se ha denominado las "cuatro erres" del movimiento indígena: representación, reconocimiento, recursos y derechos. Otorgando legitimidad a estas demandas, el DIDH consolida lo que se ha dado en Ilamar "indigenismo" como fenómeno transcultural genuinamente global, que ha favorecido que numerosos individuos redescubran y reclamen con orgullo su condición de "indígenas", contestando así la asociación de esta identidad a estereotipos exclusivamente negativos (pobreza, analfabetismo, infradesarrollo, etcétera).

Sin duda, el DIDH ha jugado un rol importante en este cambio de conciencia, así como en la connotación de corriente de liberación adquirida por el movimiento indígena, ininteligible desde una óptica estrictamente individualista de los derechos humanos. El germen de la afirmación de esta dimensión grupal de los derechos indígenas cabe situarlo en el derecho a la autodeterminación de los pueblos incluido en la Carta de Derechos Humanos de la ONU y que inspiró en buena parte el proceso de descolonización. Pero, sin duda, la aprobación de la DDPI el 13 de septiembre de 2007 marca un hito fundamental en el afianzamiento de un proceso de empoderamiento de los pueblos indígenas. La Declaración no sólo prohíbe expresamente el genocidio, la asimilación forzada, la discriminación y la explotación de los individuos indígenas, sino que, como he señalado, atribuye directamente a sus pueblos derechos que tienen que ver con el territorio, los recursos y el autogobierno.

26 DWORKIN, Ronald. "Rights as Trumps". En: WALDRON Jeremy. Theories of Rights. Oxford: Oxford University Press, 1984, pp. 152-167. 
Aunque la mayoría de los analistas admiten que la DDPI reconoce derechos colectivos, el significado e impacto de esta categoría de derechos continúan siendo polémicos. El temor que subyace a los planteamientos más críticos es que, en caso de conflicto, los derechos del grupo acaben triunfando sobre los derechos individuales de sus miembros y, por tanto, que el reconocimiento de derechos indígenas termine, paradójicamente, restringiendo los derechos humanos de los miembros más vulnerables, como las mujeres o los niños. Este asunto enlaza con la difícil cuestión que se plantea en la próxima respuesta.

\section{Aporte del DIDH}

\section{ARESIO VALIENTE}

Poco a poco fueron incorporándose los derechos de los pueblos indígenas en los instrumentos internacionales de derechos humanos. Los pueblos indígenas recorrieron muchos caminos y pasó mucho tiempo antes de que los Estados incluyeran en los tratados internacionales los derechos de los pueblos indígenas. Fue por la insistencia de los pueblos indígenas que se incluyeron los derechos de éstos en los instrumentos de derechos humanos.

Las Constituciones latinoamericanas en sus inicios no aceptan conceptos propios de los pueblos indígenas, que se diferencian de otras culturas, como el de colectividad. Algunos de estos conceptos y normas, poco a poco fueron incorporados en los instrumentos internacionales de derechos humanos.

Por otra parte, existen principios de derecho indígena que chocan con los principios de derechos humanos. En algunas comunidades indígenas se aplica como sanción el destierro del homicida; para el mundo de derechos humanos esta pena constituye una violación a los derechos humanos o a la Constitución. Los pueblos indígenas aplican dicha sanción para prevenir la comisión de venganza por parte de la familia afectada por el homicidio.

Hoy, no cabe duda de la existencia de otras formas de derecho y principios en que se basan los seres humanos, para relacionarse entre sí y con la naturaleza. Los pueblos indígenas siempre han contado con normas, escritas o no, que resuelven sus conflictos sociales; igualmente, éstas han servido para relacionarse con la naturaleza.

\section{RAQUEL Z. YRIGOYEN}

3. Aporte del DIDH

El derecho internacional ha dado un gran avance en el reconocimiento de derechos colectivos de los pueblos indígenas a través de la adopción de instrumentos internacionales como el Convenio 169 de la OIT y la DDPI. Asimismo, el sistema interamericano ha desarrollado una doctrina y jurisprudencia importante que reconoce derechos colectivos indígenas, al igual que los Ilamados "órganos cuasi jurisdiccionales" de Naciones Unidas, los que han dictado recomendaciones sobre derechos colectivos ${ }^{27}$. El derecho internacional también ha reconocido los derechos intrínsecos de los pueblos indígenas, los que constituyen otra fuente de derechos colectivos de tales pueblos ${ }^{28}$.

27 Ver, YRIGOYEN, Raquel. "A los veinte años del Convenio 169 de la OIT: Balance y retos de implementación de los derechos de los pueblos indígenas en Latinoamérica", op. cit., pp. 30 y 31.

28 ONU. Declaración de las Naciones Unidas sobre los Derechos de los Pueblos Indígenas. Aprobada el 13 de septiembre de 2007, considerando séptimo. 
El Convenio 169 de la OIT busca superar las políticas asimilacionistas que orientaban el convenio anterior, y establece derechos colectivos de los pueblos indígenas considerando las aspiraciones de los pueblos a controlar sus instituciones y formas de vida y desarrollo. De ahí se desprende el reconocimiento de las instituciones y derecho consuetudinario de los pueblos indígenas. El Convenio 169 de la OIT, al haber sido ratificado por varios países latinoamericanos, ha servido de fundamento para reformas constitucionales y legales internas, políticas públicas y desarrollo jurisprudencial.

La adopción de la DDPI en 2007 refuerza y amplía el horizonte de derechos de los pueblos indígenas, fundándolos en la igual dignidad de los pueblos y su derecho a determinar libremente su destino. La DDPI plantea la necesidad de reparar las injusticias históricas que se originan en la conquista y la colonización y cuyas consecuencias se heredan hasta nuestros días. La novedad de la DDPI reside en reconocer la igual dignidad de todos los pueblos y la libre determinación de los pueblos indígenas. Además, la DDPI condensa los avances del derecho internacional en la materia, reconociendo de modo expreso el derecho intrínseco de los pueblos indígenas, sus sistemas jurídicos, territorios, y desarrolla el derecho al consentimiento previo, libre e informado.

Tanto el Convenio 169 de la OIT como la DDPI reconocen los sistemas jurídicos indígenas en el marco del reconocimiento del derecho de los pueblos a su autonomía y el control de sus instituciones, forma de vida y desarrollo.

La jurisprudencia de la Corte IDH ha reconocido a los pueblos indígenas como titulares de derechos colectivos a la tierra y territorio, consulta y consentimiento previo, libre e informado, reparaciones y a su propio derecho consuetudinario. Desde 1993, con el caso Aloeboetoe y otros vs. Surinam ${ }^{29}$, hasta el caso más reciente Masacres de Río Negro vs. Guatemala ${ }^{30}$, la Corte IDH ha tenido en cuenta a las autoridades y al derecho consuetudinario de modo uniforme. En el primer caso, la Corte IDH reconoció el derecho consuetudinario familiar del pueblo Saramaca, obligando al Estado de Surinam a efectuar reparaciones no en base al derecho civil familiar, sino que en el derecho consuetudinario del pueblo Saramaca. En algunos casos ha especificado las normas, valores y los sistemas de control social, métodos de toma de decisiones ${ }^{31}$ y ha tenido en cuenta "las formas tradicionales de resolución de conflictos y tradición oral de la cultura", como en el caso Masacre de Plan Sánchez vs. Guatemala ${ }^{32}$.

29 Corte IDH. Caso Aloeboetoe vs. Surinam. Reparaciones y Costas. Sentencia de 10 de septiembre de 1993. Serie C No. 15, párr. 62.

30 Corte IDH. Caso Masacres de Río de Negro vs. Guatemala. Excepción Preliminar, Fondo, Reparaciones y Costas. Sentencia de 4 de septiembre de 2012. Serie C No. 250, párr. 177.

31 Corte IDH. Caso del Pueblo Saramaka vs. Surinam. Excepciones Preliminares, Fondo, Reparaciones y Costas. Sentencia de 28 de noviembre de 2007. Serie C No. 172, párr. 134; Caso del Pueblo Saramaka vs. Surinam. Interpretación de la Sentencia de Excepciones Preliminares, Fondo, Reparaciones y Costas. Sentencia de 12 de agosto de 2008. Serie C No. 185, párr. 13; Caso Pueblos Indígena Kichwa de Sarayaku vs. Ecuador. Fondo y Reparaciones. Sentencia de 27 de junio de 2012. Serie C No. 245, párr. 177.

32 Corte IDH. Masacre Plan de Sánchez vs. Guatemala. Reparaciones y Costas. Sentencia de 19 de noviembre de 2004. Serie C No. 116, párrs. 16, 49 y 85. 


\section{Límites a las prácticas culturales indígenas}

Desde una perspectiva de respeto a la dignidad y los derechos humanos consagrados en las constituciones nacionales y los tratados internacionales: ies posible y/o justificable imponer límites a las prácticas culturales indígenas o sistemas legales indígenas?

4. Límites a las prácticas culturales indígenas

\section{ALEXEI JULIO-ESTRADA}

Lo relacionado con los límites de los sistemas normativos indígenas, derivados del respeto de los derechos individuales reconocidos en las Constituciones y en los tratados internacionales de derechos humanos, es sin duda uno de los temas más difíciles de resolver por las jurisdicciones nacionales. Nuevamente, creo que resulta más útil una respuesta basada en una experiencia concreta como el caso colombiano, para dar algunas luces sobre la materia. Desde sus primeras decisiones la Corte Constitucional de Colombia defendió la idea de que era necesario, para preservar los usos y costumbres de los pueblos indígenas, respetar el más alto grado posible de autonomía en las decisiones adoptadas por sus autoridades tradicionales indígenas. De manera tal que se estableció una suerte de consenso intercultural mínimo en torno a ciertas prohibiciones que no podían ser trasgredidas por las decisiones adoptadas por dichas autoridades, bajo el entendido que de esta manera se preservaban derechos considerados importantes tanto por las comunidades indígenas como por la cultura mayoritaria ${ }^{33}$. Así las autoridades indígenas no pueden imponer la pena de muerte, la de esclavitud e, igualmente, se prohíbe la tortura y el destierro.

Ahora bien, este consenso es resultado de dos aproximaciones: (i) por una parte, el estudio de los usos y costumbres de los pueblos indígenas asentados en el territorio colombiano y la verificación de que la mayoría de éstos no admite penas de esta naturaleza y (ii) el examen de los tratados internacionales de derechos humanos en lo que hace referencia a las cláusulas de derechos intangibles (artículo 27.2 de la CADH y 4.2 del PIDCP).

Sin embargo, la Corte Constitucional entiende que en cada caso concreto hay que examinar con detenimiento las prácticas culturales de la comunidad indígena involucrada y que en esta medida el juez constitucional tiene que examinar sus usos y costumbres para de esta manera entablar una especie de diálogo intercultural ${ }^{34}$. Así, se ha entendido que ciertos castigos corporales tales como los fuetazos o el cepo no entran dentro del concepto de tortura y están, por lo tanto, permitidos; o que la expulsión de un individuo de la comunidad no constituye, prima facie, una pena de destierro. Empero, cada vez se presentan casos más complejos, sobre todo los relacionados con mujeres que reclaman protección estatal con el argumento de que las autoridades tradicionales indígenas no sancionan con el rigor debido delitos relacionados con la violencia de género. También son particularmente problemáticos aquellos casos en los que resultan afectados niños y niñas, pues la protección del interés superior del menor lleva a cuestionar algunas de las prácticas adoptadas por ciertos pueblos indígenas. Hasta ahora ${ }^{35}$, aun en estos casos se ha privilegiado la autonomía de las autoridades indígenas para aplicar sus propios usos y costumbres. Creo que esta solución

\footnotetext{
33 Corte Constitucional de Colombia. Sentencia T-349 de 8 de agosto de 1996 reiterada por las sentencias SU-510 de 18 de septiembre de 1998 y T-812 de 27 de octubre de 2011.

34 Corte Constitucional de Colombia. Sentencia T-523 de 15 de octubre de 1997.

35 Corte Constitucional de Colombia. Sentencia T-617 de 5 de agosto de 2010 y sentencia T-002 de 11 de enero de 2012.
} 
ha sido adecuada porque tiene la necesaria flexibilidad para estudiar los casos concretos, sin prescindir de la idea de que existen límites para las prácticas culturales de los pueblos indígenas.

4. Límites a las prácticas culturales indígenas

\section{JOSÉ ANTONIO RIVERA}

El proceso de reconocimiento de los derechos colectivos de los pueblos indígenas, tanto en el ámbito del DIDH como en el ámbito del derecho

interno de los Estados, ha generado una tensión entre la visión universal individual abstracta de los derechos humanos y la visión del particularismo colectivo concreto de los derechos. En particular, esta resistencia se ha visto en la aplicación de su sistema jurídico indígena y en la del derecho a la identidad cultural.

Esa tensión no debe ser concebida como una grave contradicción que vaya a ser saldada con la eliminación de una de las visiones. Al contrario, debe ser asumida como un reto para lograr un avance en la concepción oficial de los derechos humanos, logrando insertar la perspectiva emergente de la particularidad de los derechos indígenas -de la diversidad cultural- a la perspectiva universal.

Al respecto, Xabier Etxeberria ${ }^{36}$ plantea algunas estrategias. En primer lugar, haciendo suya la propuesta de M. Walzer, propone distinguir, entre unos mínimos derechos-deberes básicos de alcance universal en los que el consenso es fácil y que no se imponen a las diferencias (derecho a no ser despojado de la vida y de la libertad -oposición a la dominación-, respeto a las creaciones culturales y derecho a la comunidad) y derechos-deberes que ya no son el resultado de nuestra común humanidad, sino que tienen carácter local y particular, apoyados en concepciones culturales particulares de los bienes sociales. En segundo lugar, propone afirmar, con formulaciones prácticamente unívocas de validez universal, una serie de derechos mínimos básicos y fuertes, que suponen los correspondientes deberes para los Estados y los ciudadanos. En tercer lugar, propone afirmar otra serie de derechos de modo genérico, que inevitablemente deberán tener marcadas encarnaciones culturales e históricas particulares. En cuarto lugar, utilizando una expresión de Kymlicka, sostiene que pueden plantearse "derechos diferenciales en función de las culturas grupales". El profesor Etxeberria concluye señalando que "se trata de una universalidad que, asumiendo a nuestro modo unas categorías de Todorov, no puede ser planteada ya como universalidad 'de partida' (en la que desde una cultura se da ya todo hecho como válido para todos), ni siquiera 'de llegada' (porque la universalidad se nos muestra como horizonte hacia el que siempre hay que avanzar), sino, precisamente por esta última razón, de 'recorrido', de un recorrido protagonizado interculturalmente" ${ }^{\prime 37}$.

En el contexto referido, cabe señalar que un eventual conflicto entre la dignidad humana y los derechos humanos consagrados por las constituciones nacionales y los tratados internacionales con las prácticas culturales indígenas o sistemas legales indígenas, no debe resolverse a partir de una visión unilateral, ya sea la universal individual abstracta o la del particularismo colectivo concreto, sino a partir de una concepción intercultural. Como sostiene Asier Martínez de Bringas, se debe:

[...] tener en cuenta que todas las culturas tienen concepciones propias sobre cómo entender la 'dignidad humana'; los conflictos para la construcción de un pacto intercultural

36 ETXEBERRÍA, Xabier. "La tradición de los derechos humanos y los pueblos indígenas: una interpelación mutua en Pueblos Indígenas y Derechos Humanos". En: BERRAONDO, Mikel (Coord.). Pueblos indígenas y derechos humanos. Bilbao: Instituto de Derechos Humanos, Universidad de Deusto, 2006, pp. 77-80.

37 Ibídem, p. 80. 
comienzan cuando estas concepciones son diferentes y no se expresan como derechos humanos, según el formato construido y exigido por Occidente. Por ello, será necesario estar atento a aquellas consideraciones de la dignidad humana que en cada cultura están más abiertas a la interpretación y diálogo con otras culturas, puesto que en ellas existen creativas referencias para la consolidación de otra cultura de los derechos humanos ${ }^{38}$.

\section{Límites a las prácticas culturales indígenas}

\section{NEUS TORBISCO}

Los derechos indígenas reconocidos por el DIDH son susceptibles de implementarse de formas distintas. Aun así, el derecho al autogobierno suele traducirse en la devolución de poderes por parte del Estado, de tal modo que los pueblos indígenas recuperan una cierta autonomía, erigiéndose en autoridades oficiales en sus propios territorios con competencias para preservar y desarrollar el cuerpo normativo heredado. Aunque las historias concretas difieran, la genealogía constitucional de lo que Kirsty Gover denomina settler state $^{39}$ ha admitido progresivamente la diferencia indígena como factor relevante en el derecho público. A menudo, la atribución de autogobierno a los pueblos indígenas conlleva admitir la existencia de múltiples centros de creación y aplicación normativa sin que exista, en última instancia, una única fuente formal de autoridad que unifique y dote de coherencia al ordenamiento resultante. El pluralismo jurídico emerge, pues, como resultado de esta transformación, asociado a una imagen de incerteza y falta de coherencia que justifica algunas de las críticas más fundadas a los derechos indígenas.

En efecto, si admitimos que una de las funciones centrales de las Constituciones modernas es garantizar los derechos humanos, ¿cabe justificar la incorporación sin límites del derecho indígena, incluso si con ello se legitiman prácticas o costumbres difícilmente compatibles con los derechos humanos individuales incorporados a los ordenamientos jurídicos domésticos? El temor es que, en la práctica, los derechos colectivos sirvan para otorgar carta blanca a quienes detentan el poder en el seno del grupo para reforzar prácticas opresivas o discriminatorias de los miembros más vulnerables. Es lo que Ayelet Shachar denomina "la paradoja de la vulnerabilidad multicultural" ${ }^{40}$ : la promoción de la igualdad entre grupos puede terminar reforzando o incluso agravando las desigualdades existentes dentro del grupo, empeorando la posición de las denominadas "minorías dentro de las minorías".

Esta objeción se ha planteado con especial énfasis por parte de la crítica feminista. Como señaló Susan Okin ${ }^{41}$, el derecho a la educación se niega a muchas niñas en nombre de la integridad cultural. También se defienden la preservación de la virginidad o el matrimonio forzado como instrumentos de preservación cultural. Estas situaciones ilustran no sólo las tensiones entre multiculturalismo y feminismo, sino que las dificultades para conciliar derechos humanos individuales

38 MARTÍNEZ DE BRINGAS, Asier. "Los pueblos indígenas ante la construcción de los procesos multiculturales. Inserciones en los bosques de la biodiversidad". En: BERRAONDO, Mikel (Coord.). Pueblos Indígenas y Derechos Humanos. Bilbao: Instituto de Derechos Humanos, Universidad de Deusto, 2006, p. 86.

39 GOVER, Kirsty. Tribal Constitutionalism. States, Tribes and the Governance of Membership. Oxford: Oxford University Press, 2011

40 SHACHAR, Ayelet. "The Paradox of Multicultural Vulnerability. Individual rights, Identity Groups and the State". En: JOPPKE, Christian y LUKES, Steven (Eds.). Multicultural Questions. Oxford: Oxford University Press, 1999, pp. 87-111.

41 OKIN, Susan. "Is Multiculturalism Bad for Women?". Originalmente publicado en: Boston Review, Octubre/Noviembre 1997 y reproducido en la antología con el mismo título editada por Joshua Cohen y Mathew Howard, y publicada por Princeton University Press en 1999. 
y derechos colectivos. Aunque se trata de un problema de enorme complejidad, me parece importante tener en cuenta las siguientes observaciones.

A menudo se traen a colación casos tan extremos o penosos con el fin de argumentar en contra del reconocimiento de derechos colectivos tout court. Pero esta conclusión es precipitada. No debe olvidarse que, de hecho, el ejercicio de los derechos individuales también puede realizarse de manera abusiva (por ejemplo, la libertad de expresión puede utilizarse para degradar una determinada identidad) y, sin embargo, no por ello decidimos suprimir los derechos en cuestión, sino que, en todo caso, tratamos de delimitar las formas legítimas de ejercicio. La pregunta importante es, pues, cómo balanceamos derechos individuales y derechos colectivos, y quién puede decidir al respecto. Una respuesta posible pasa por restringir el reconocimiento de derechos a los grupos que tienen intención de respetar la autonomía de todos sus miembros, inclusive los sub grupos más vulnerables ${ }^{42}$. Sin embargo, ¿quién debería decidir qué constituye una restricción inaceptable? Ciertamente, se suele asumir que esta decisión corresponde al Estado, apelando a la necesidad de proteger a sus miembros. Pero este patrón suele degenerar en un sesgo paternalista contrario a las minorías culturales, especialmente si se trata de pueblos indígenas.

Una alternativa menos arriesgada en este sentido es que, como regla general, el Estado se abstenga de interferir en el ejercicio del autogobierno indígena, pero en cambio proteja fuertemente el derecho individual a salir del grupo, esto es, apoye a los disidentes. Sin embargo, este enfoque "contractualista", que parte de la libertad de asociación, tergiversa la relevancia que la pertenencia cultural tiene para el individuo concreto, inclusive para los miembros más vulnerables del grupo. Las mujeres indígenas, por ejemplo, difícilmente estarán satisfechas de disponer de la opción de abandonar el grupo.

Una posible vía de conciliación pasaría por promover un modelo de aproximación a estos conflictos que ponga el énfasis en la participación de los miembros más vulnerables de estos grupos en los procesos de resolución de los mismos. La promoción de formas inclusivas de participación y deliberación intra e intergrupales reacciona contra la omnipresencia del Estado e insta a una política del compromiso tanto entre Estado y minorías como entre los grupos que internamente están en desacuerdo. Los derechos de salida, así como la intervención coactiva del Estado, pueden seguir desempeñando un rol, pero sólo como último recurso ${ }^{43}$.

\section{Límites a las prácticas culturales indígenas}

\section{ARESIO VALIENTE}

No existe cultura perfecta e inmutable. La cultura indígena no es perfecta, ni la cultura latina lo es; como tampoco lo son otras culturas que existen en el mundo. Todas las culturas evolucionan y de acuerdo con su realidad social, política, económica y espiritual, van creando su propia cosmovisión.

42 Esta es la vía de resolución más compatible con la justificación liberal de los derechos colectivos en la teoría de Kymlicka. Su influyente argumento se basa en la conexión entre libertad individual y pertenencia cultural, y por ello se impone una restricción importante a los grupos que reclaman derechos con el fin de imponer restricciones internas a sus miembros. KYMLICKA, Will, Multicultural Citizenship, op. cit., p. 35.

43 He intentado defender este enfoque participativo en, TORBISCO CASALS, Neus. "Feminismo, multiculturalismo y derechos culturales". En: DO AMARAL, Alberto et. al. (Ed.). El Constitucionalismo en transición. Seminario en Latinoamérica de Teoría Constitucional y Política. Buenos Aires: Libraria, pp. 134-170. 
La cosmovisión no sólo es la valoración que una cultura tiene sobre el mundo que lo rodea, sino que también de todos los valores sociales, culturales, económicos, espirituales y políticos. Los pueblos indígenas cuentan con su propia cultura, por ende, su propia cosmovisión.

Se deben reconocer los aportes de los pueblos indígenas, a través de sus prácticas culturales y sus sistemas legales. Uno de los aportes de los pueblos indígenas en materia de derecho es su filosofía y su relación espiritual con la Naturaleza. El concepto de la Madre Naturaleza es parte fundamental del derecho ambiental, el cual hoy en día es parte del desarrollo social, económico y espiritual de la humanidad.

No sólo se deben imponer límites a las prácticas culturales o sistemas legales de los pueblos indígenas, sino que también a otras culturas, siempre y cuando violen los derechos fundamentales de los seres humanos. En todas las culturas existen elementos positivos que favorecen a la humanidad; y también existen factores negativos que deben ser desechados.

Los elementos positivos de las culturas indígenas deben ser incorporados en los nuevos instrumentos de derechos humanos, para que sea integral el desarrollo de la humanidad.

4. Límites a las prácticas culturales indígenas

\section{RAQUEL Z. YRIGOYEN}

El derecho internacional establece como límite al derecho consuetudinario indígena no vulnerar los derechos humanos (de sus miembros o terceros), bajo el principio de conformidad o compatibilidad entre el derecho consuetudinario o los sistemas jurídicos indígenas y los derechos humanos (Convenio 169 de la OIT, artículo 8.2 y DDPI, artículo 34).

(i) En caso de que hubiera un conflicto entre el derecho consuetudinario indígena y los derechos humanos, el Convenio 169 establece que "deberán establecerse procedimientos para solucionar los conflictos que puedan surgir en la aplicación de este principio" (Convenio 169 de la OIT, artículo 8.2 in fine).

(ii) El establecimiento de estos procedimientos deberá ser consultado con los propios pueblos indígenas (Convenio 169 de la OIT, artículo 6).

(iii) Todo procedimiento, mecanismo o institución encargada de resolver los conflictos entre derecho consuetudinario indígena y derechos humanos deberá contar con la participación de los mismos pueblos indígenas (Convenio 169 de la OIT, artículo 6, inc. 1. b).

(iv) La aplicación del Convenio debe darse de forma sistemática y coordinada con los pueblos indígenas (Convenio 169 de la OIT, artículo 2).

En el paradigma monocultural del derecho internacional y constitucional, que presupone que sólo los occidentales pueden definir, interpretar y aplicar los derechos humanos, éstos deben ser impuestos de modo heterónomo a los pueblos indígenas.

Desde un paradigma pluralista, que ahora está reconocido en el derecho internacional y constitucional, también los pueblos indígenas son sujetos con dignidad que tienen el derecho de participar en la definición de los derechos, los límites y los mecanismos para hacerlos cumplir en el marco de una convivencia pacífica entre pueblos. Desde este paradigma es que debe interpretarse la provisión del derecho internacional que establece que el límite al derecho consuetudinario está dado por los derechos humanos. 
La participación de los pueblos indígenas en la definición de los derechos fundamentales ya se da actualmente. Así por ejemplo, gracias al aporte indígena, hay nuevos derechos que se han reconocido en las Constituciones y en el DIDH. En este momento se garantiza la participación institucional de los pueblos en las decisiones que les afectan. La Constitución de Bolivia, como ejemplo, ha establecido una composición plurinacional del Tribunal Constitucional que es la instancia encargada de resolver los conflictos entre sistemas indígenas y derechos humanos. Esta participación de autoridades indígenas en los procedimientos y mecanismos institucionales encargados de resolver los conflictos entre normas o prácticas del derecho consuetudinario indígena y provisiones de derechos humanos posibilita la comprensión intercultural de los hechos y derechos involucrados. Asimismo, la participación de autoridades indígenas en estos procedimientos permite realizar el principio de la igual dignidad de pueblos y culturas que ha reconocido el derecho internacional de los derechos humanos (DDPI, artículo 2).

En una sentencia progresista, la Corte Constitucional de Colombia resolvió esta aparente contradicción constitucional, diciendo claramente que la adopción del principio del pluralismo podría quedar vacía si la jurisdicción indígena tuviese que someterse a toda la Constitución y leyes ${ }^{44}$. De ahí, la Corte estableció sólo cuatro mínimos fundamentales, esto es, que las decisiones de la jurisdicción indígena no podían incluir pena de muerte, tortura, esclavitud, y que debían ser de algún modo predecibles, esto es, que debían respetar su propio debido proceso. Este es un avance en cuanto a la comprensión de los límites, pero resuelto por un organismo sin participación institucional indígena. Actualmente, el derecho comparado constitucional permite pensar que no sólo las resoluciones de las Cortes deben ser plurales, sino que también la composición misma de las Cortes, para poder reflejar verdaderamente el concepto de la igual dignidad de pueblos y culturas.

44 Ver, YRIGOYEN, Raquel. "El Horizonte del constitucionalismo pluralista: del multiculturalismo a la descolonización", op. cit., pp. 139-159. 
